Physiology, metabolism

\title{
Lactic acid production during the associated and the deceleration growth phases of Lactobacillus helveticus cultivated in various conditions and media
}

\author{
Abdeltif AMRANE* \\ Laboratoire des Procédés de Séparation (Unité associée INRA), Université de Rennes 1, \\ Campus de Beaulieu, Bât. 10A, 263 avenue du Général Leclerc, \\ CS 74205, 35042 Rennes Cedex, France
}

\begin{abstract}
Both growth phases, associated and deceleration, must be considered in the optimization of the lactic acid fermentation. The objective is to maximize the part of lactic acid produced during growth, firstly by a growth-associated mechanism and during the subsequent deceleration phase. Analysis of both growth phases has been carried out from the comparison of growth and lactic acid production rates by $L$. helveticus. The linked or the partially linked production during the growth-associated and the deceleration growth phases, respectively, increased when the culture conditions were close to the optimal ones; in this case, almost half of the final amount of lactic acid is produced during the short $(2 \mathrm{~h})$ deceleration growth phase. The part of lactic acid produced during growth, as well as the growth-associated coefficient A (corresponding to the product on biomass yield $\mathrm{Y}_{\mathrm{P} / \mathrm{X}}$ ), are mainly controlled by the culture conditions (media composition, $\mathrm{pH}$, lactate and undissociated lactic acid concentrations), but are not affected by seed culture conditions (media, length and inoculation level). High values of the growth and production rates resulting in a strong production during both growth phases, associated and deceleration, corresponded to low values of the product on biomass yield $\mathrm{Y}_{\mathrm{P} / \mathrm{X}}$.
\end{abstract}

lactic acid bacteria / growth rate / production rate / batch culture

Résumé - Étude de la production d'acide lactique durant les phases de croissance associée et de ralentissement pour Lactobacillus helveticus cultivé dans différentes conditions et milieux. Les deux phases de croissance, associée et de ralentissement, doivent être considérées lors de l'optimisation de la fermentation lactique, la phase associée correspondant à la somme de deux phases, la latence et la phase exponentielle. L'objectif étant de maximiser la part d'acide lactique produite durant la croissance, d'abord par un mécanisme associé à cette dernière, puis durant le ralentissement qui suit. L'analyse de ces deux phases a été menée par comparaison des vitesses de croissance et de production de L. helveticus. La part d'acide, produite par un mécanisme couplé à la croissance durant la phase associée, puis de manière partiellement associée durant la phase de ralentissement,

\footnotetext{
* Tel.: (33) 2992829 52; fax: (33) 2992829 57; e-mail: abdeltif.amrane @ univ-rennes1.fr
} 
augmente lorsque les conditions de culture se rapprochent des conditions optimales, c'est-à-dire lorsque l'on passe d'une limitation azotée de la croissance à une limitation carbonée (au-delà de $20 \mathrm{~g} \cdot \mathrm{L}^{-1}$ d'extrait de levure ajoutés dans le milieu). Dans ce dernier cas, près de la moitié de l'acide lactique est produit durant la courte phase $(2 \mathrm{~h})$ de ralentissement de la croissance. En effet, la vitesse de production reste proche de son maximum durant la courte phase de ralentissement. La part d'acide produit durant la croissance, ainsi que le coefficient de production associée à la croissance A (correspondant au rendement acide lactique produit sur biomasse formée $\mathrm{Y}_{\mathrm{P} / \mathrm{X}}$ ), dépendent principalement des conditions de culture, c'est-à-dire de la composition du milieu, du pH, ainsi que des concentrations en anion lactate et en acide non dissocié. Par contre, ces deux paramètres ne sont pas affectés par les conditions de préculture, c'est à dire le milieu, la durée de cette dernière, ainsi que le taux d'inoculation. Des valeurs élevées des vitesses de croissance et de production ont pour conséquence une forte production durant les phases de croissance associée et de ralentissement et correspondent à de faibles valeurs du rendement produit sur biomasse $\mathrm{Y}_{\mathrm{P} / \mathrm{X}}$.

bactérie lactique / vitesse de croissance / vitesse de production / culture discontinue

\section{INTRODUCTION}

Four steps can be identified during the growth of L. helveticus: the growth-associated phase, the deceleration growth phase, the stationary state and the decline of cells. The beginning of this latter phase always coincides with the end of lactic acid production, since resting cells are unable to use the carbon components released by autolysis [3]. Therefore, the death phase has no significance for lactic acid production.

The growth-associated phase includes the lag phase and the following exponential growth. The former is very short with regards to the usual seed culture conditions, i.e. a large nitrogen supplementation, and a high inoculation level, $11 \%[2,4]$. The end of the associated phase is indicated by an inflexion point on the growth kinetics, i.e. the maximum for the growth rate [5]. The lactic acid production rate increased during this phase to its maximum value, always achieved in the beginning of the deceleration growth phase, i.e. shortly after maximum growth rate [5].

For a complete conversion of the lactose into lactic acid in the minimum time, i.e. the maximum for the mean production rate, it is necessary to identify the main factors affecting growth. During the stationary state, lactic acid is produced by a maintenance mechanism at low rate [5]. Therefore, the objective is to maximize the part of lactic acid produced during growth, firstly by a growth-associated mechanism and during the subsequent deceleration growth phase. For this purpose, high growth and production rates must be achieved during the growth-associated phase, resulting in large amounts of lactic acid produced also during the subsequent short deceleration growth phase.

Usually, the association between growth and production is analyzed by means of the graph of the specific production rate $\left(q_{p}\right)$ versus the specific growth rate $(\mu)$. In the case of a partial association between both parameters, the following equation fitted the experimental data well, as shown by Luedeking and Piret [13]:

$$
q_{p}=A \cdot \mu+B,
$$

with A and B the coefficients for growthand non-growth-associated production, respectively.

To draw the corresponding plot, the experimental growth and production data have to be derived. The lactic acid concentration can be accurately deduced from the 
quantity of $\mathrm{NaOH}$ added for the $\mathrm{pH}$ correction; on the contrary, there is a large experimental error on the cellular concentration, especially in the beginning of the culture. In addition, it has been previously demonstrated that the plot $\mathrm{q}_{\mathrm{p}}$ versus $\mu$ did not allow to clearly differentiate distinct situations [3].

Therefore, instead of the graph $q_{p}$ versus $\mu$, the part of lactic acid produced by an associated mechanism has been deduced from the graph lactic acid produced versus biomass formed. The amount of lactic acid produced by an associated mechanism corresponds to the linear part of the curve:

$$
\mathrm{p}-\mathrm{p}_{0}=\mathrm{A} .\left(\mathrm{x}-\mathrm{x}_{0}\right) .
$$

During this phase, the yield product on biomass formed $\mathrm{Y}_{\mathrm{P} / \mathrm{X}}$ (corresponding to the slope of the curve) remained constant and equal to the growth-associated coefficient $\mathrm{A}$; then, this yield increased during the deceleration growth phase, until an infinite value at the beginning of the stationary state [3].

The coefficient A can be accurately deduced from the plot corresponding to equation (2); however, an arbitrary criterion for the end of the linking between growth and production has to be defined to determine the part of the coupled production and its length. Moreover, the deceleration growth phase appeared difficult to define by means of this plot. On the other hand, from the comparison of the growth and production rates, the length of the different growth phases could be easily determined, as previously shown [5], since the time-variable appeared explicitly; then the part of the coupled production could be deduced. The coefficient A corresponds to the ratio of the production rate on the growth rate during the associated phase.

The effect of some culture parameters on the growth and production linking have been pointed out in the available literature. However, contradictory results concerning the effect of the culture $\mathrm{pH}$ can be found: the uncoupling increase at acidic $\mathrm{pH}$ for some authors [15, 17], while Norton et al. [14] obtained a low value for the coefficient for non-growth-associated production $\mathrm{B}$ at pH 4.3 (0.01). Moreover, an effect of the nitrogen limitation has also been reported [16]. On the contrary, the literature seems very poor concerning the effect of culture parameters on the deceleration growth phase of lactic acid bacteria [7, 9].

Examination of the available bibliography shows that the growth-associated phase has frequently been assimilated to growth, and the deceleration phase omitted. On the contrary, to our knowledge, systematic analysis of the effect of the main culture parameters on both of the above growth phases, associated and deceleration, is not available. Such a study will be the aim of the present paper, and will be essentially conducted from the analysis of the growth and production rates.

\section{MATERIALS AND METHODS}

\subsection{Microorganism}

Lactobacillus helveticus strain milano used throughout this work was kindly supplied by Dr. A. Fur (Even S.A., Ploudaniel, France). Stock cultures were maintained on $10 \%(\mathrm{w} / \mathrm{v})$ skim milk and deep frozen at $-16{ }^{\circ} \mathrm{C}$. As required, these cultures were thawed and reactivated by two transfers in $10 \%(\mathrm{w} / \mathrm{v})$ sterilized skim milk $\left(42{ }^{\circ} \mathrm{C}\right.$, $24 \mathrm{~h})$.

\subsection{Media}

Whey permeate powder (Armor-Protéines, St.-Brice, France) was used as a carbon source; the powder was reconstituted at $57 \mathrm{~g} \cdot \mathrm{L}^{-1}$, corresponding to a lactose concentration of $48 \mathrm{~g} \cdot \mathrm{L}^{-1}$. Before use, the permeate was clarified by a heat / calcium process [10]: it was supplemented with $3 \mathrm{~g} \cdot \mathrm{L}^{-1} \mathrm{CaCl}_{2}, 2 \mathrm{H}_{2} \mathrm{O}$, the $\mathrm{pH}$ was settled at 7.3, and the solution was pumped through two heat exchangers at $80^{\circ} \mathrm{C}$ and $16^{\circ} \mathrm{C}$ 
respectively (mean residence time: $20 \mathrm{~s}$ ). The solution was left to decant overnight at $4{ }^{\circ} \mathrm{C}$, and the supernatant was then supplemented with a range of yeast extract concentration $\left(2,5,10,20,30 \mathrm{~g} \cdot \mathrm{L}^{-1}\right)$ or $20 \mathrm{~g} \cdot \mathrm{L}^{-1}$ yeast extract and $5 \mathrm{~g} \cdot \mathrm{L}^{-1}$ of both tryptic and pancreatic casein peptones (RM supplementation), for culture and seed culture media.

When needed, aliquots of $1 \mathrm{~mol} \cdot \mathrm{L}^{-1}$ lactic acid were added to RM medium in order to achieve initial concentrations $\mathrm{p}_{0}$ of $0,2,3$, and $5 \mathrm{~g} \cdot \mathrm{L}^{-1}$, corresponding to $\mathrm{pH}$ values of $5.90,4.63,4.34$, and 4.04 respectively. During each run, the $\mathrm{pH}$ was maintained at its initial value by automatic addition of $10 \mathrm{~mol} \cdot \mathrm{L}^{-1} \mathrm{NaOH}$. The same procedure was applied to a second set of culture medium for which the initial $\mathrm{pH}$ was adjusted with hydrochloric acid instead of lactic acid.

For another set of experiments, RM culture medium was supplemented with $1 \mathrm{~mol} \cdot \mathrm{L}^{-1}$ lactic acid at the required concentration $\left(10,40,50 \mathrm{~g} \cdot \mathrm{L}^{-1}\right)$, then $\mathrm{pH}$ was settled at 5.9 by the addition of $10 \mathrm{~mol} \cdot \mathrm{L}^{-1}$ $\mathrm{NaOH}$.

When needed, sodium phosphate $\mathrm{NaH}_{2} \mathrm{PO}_{4} \cdot \mathrm{H}_{2} \mathrm{O}$ corresponding to $0.16 \mathrm{~g} \cdot \mathrm{L}^{-1}$ of phosphorus, was added to the culture medium supplemented with 2 or $20 \mathrm{~g} \cdot \mathrm{L}^{-1}$ yeast extract.

\subsection{Fermentors and culture conditions}

Batch culture was carried out in a $2-\mathrm{L}$ fermentor (SET 2M, Inceltech, Toulouse, France), magnetically stirred (300 rpm), at $42{ }^{\circ} \mathrm{C}$. The $\mathrm{pH}$ was maintained at 5.9 by automatic addition of $10 \mathrm{~mol} \cdot \mathrm{L}^{-1} \mathrm{NaOH}$. The mass of the $\mathrm{NaOH}$ solution added for pH control was continuously recorded, allowing on-line calculation of the quantity of lactate anion produced at a given $\mathrm{pH}$ at each time point; the observed standard deviation was $\pm 1 \mathrm{~g} \cdot \mathrm{L}^{-1}$.

Seed culture was carried out in a $0.25-\mathrm{L}$ laboratory-designed glass fermentor equipped with a sterilizable combination glass electrode (Ingold, Paris, France), cotton plug filter, magnetic stirrer, infra-red lamp temperature control (set at $42{ }^{\circ} \mathrm{C}$ ), and an aseptic transfer line.

In addition, both fermentors were equipped with an aseptic recirculation loop (Watson-Marlow $501 \mathrm{U}$ peristaltic pump; Volumax, Montlouis, France) incorporating a laboratory-made turbidimeter. As the turbidity was continuously recorded, the total biomass could be calculated on-line after dry weight calibration; the observed standard deviation was $\pm 0.2 \mathrm{~g} \cdot \mathrm{L}^{-1}$.

Bacteria were precultivated by inoculating sterile culture medium with $0.8 \%(\mathrm{v} / \mathrm{v})$ of the second skim milk transfer. Then, $1.6 \mathrm{~L}$ of pasteurized culture medium was inoculated with $0.2 \mathrm{~L}$ seed culture $(11 \% \mathrm{v} / \mathrm{v})$ unless specified, and the reaction proceeded.

The concentration of total ( $p$ ) and undissociated (HL) lactic acid was calculated using the Henderson-Hasselbach equation $\left(\mathrm{pK}_{\mathrm{A}}=3.8\right)$, the lactate concentration () and the corresponding $\mathrm{pH}$ value:

$$
\mathrm{HL}=\frac{\mathrm{L}^{-}}{10^{\mathrm{pH}-\mathrm{pK}_{\mathrm{A}}}}
$$

and

$$
\mathrm{p}=\mathrm{HL}+\mathrm{L}^{-} .
$$

\subsection{Analytical methods}

At the end of both the preculture and culture, the final biomass, lactose, and lactic acid concentrations were determined as previously described [3].

\section{RESULTS AND DISCUSSION}

\subsection{Culture parameters determination}

From Figure 1, it clearly appears that the maximum for the growth rate, i.e. the inflexion point on the growth kinetics, also corresponds, as expected, to the end of the 
linear part of the logarithmic growth curve, i.e. the end of the exponential growth. It can also be noticed that the maximum for the production rate was always recorded a short time after maximum growth rate, which therefore indicates the end of the associated growth phase. These results have been validated for various culture media (Fig. 1), but have been successfully tested in various culture conditions.
Figure 1. Logarithmic cellular concentration $(\mathbf{\Delta})$ and growth $\mathrm{dx} / \mathrm{dt}(\boldsymbol{O})$ and production $\mathrm{dp} / \mathrm{dt}(\nabla)$ rate kinetics for $L$. helveticus growing on whey permeate supplemented with: (a) $20 \mathrm{~g} \cdot \mathrm{L}^{-1}$ yeast extract and $5 \mathrm{~g} \cdot \mathrm{L}^{-1}$ of both tryptic and pancreatic casein peptones (RM medium); (b) 20 and; (c) $10 \mathrm{~g} \cdot \mathrm{L}^{-1}$ yeast extract.

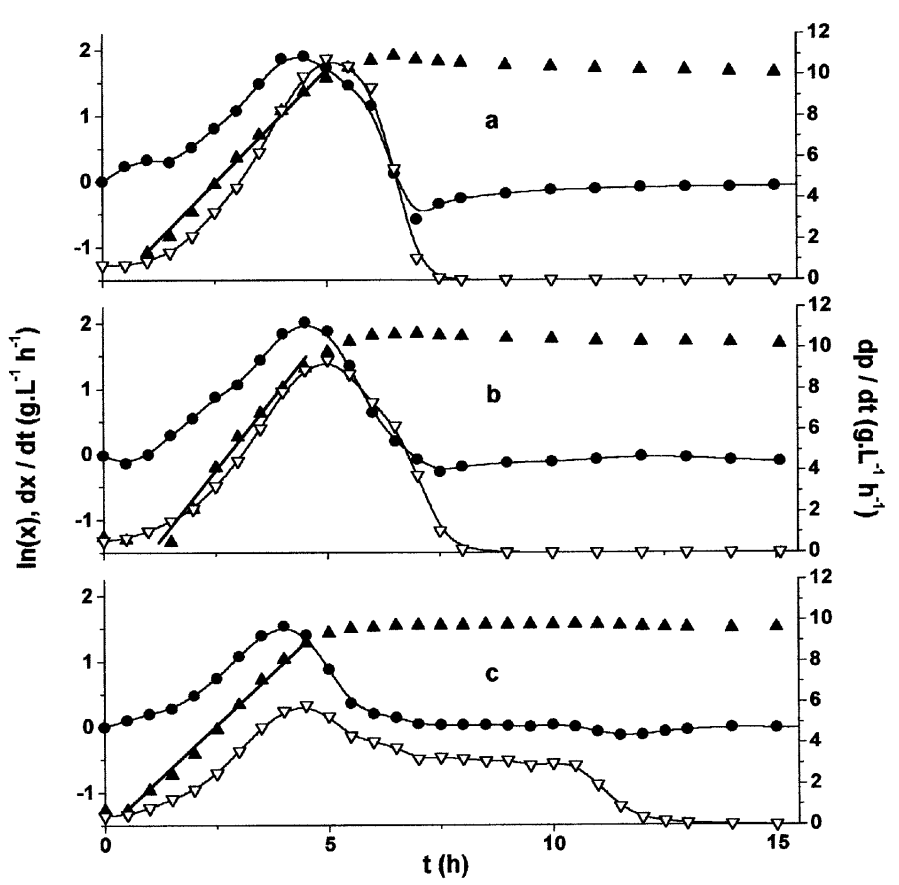

Table I. Comparison of the values obtained for the coefficient A for the growth-associated production by different methods.

A

deduced from the plot

\begin{tabular}{|c|c|c|c|c|}
\hline \multicolumn{2}{|c|}{$\begin{array}{c}\text { Nitrogen } \\
\text { supplementation }\end{array}$} & $\begin{array}{l}\text { Product on } \\
\text { hiomass vield }\end{array}$ & $\begin{array}{l}\text { Production rate } \\
\text { versus growth rate }\end{array}$ & $\begin{array}{l}\text { Ratio production } \\
\text { rate on growth rate }\end{array}$ \\
\hline \multirow{5}{*}{$\mathrm{YE}\left(\mathrm{g} \cdot \mathrm{L}^{-1}\right)$} & 2 & 10.2 & 8.7 & 10.9 \\
\hline & 5 & 5.7 & 5.1 & 5.7 \\
\hline & 10 & 3.7 & 3.3 & 3.5 \\
\hline & 20 & 4.6 & 4.6 & 4.3 \\
\hline & 30 & 5.1 & 5.1 & 4.9 \\
\hline RM & & 4.3 & 4.2 & 4.4 \\
\hline
\end{tabular}

a Slope of the curve $\mathrm{p}-\mathrm{p}_{0}$ vs. $\mathrm{x}-\mathrm{x}_{0}$.

b Slope of the curve dp/dt vs. dx/dt.

${ }^{\mathrm{c}}$ Ratio of the production rate on the growth rate during the exponential growth phase. 
In Table I the coefficients A for growthassociated production obtained in a set of runs carried out with a range of nitrogen 95 supplementations are compared. As observed, for a given culture medium, the same coefficient A, within the limits of experimental error, is deduced from the kinetics and from the rates, except for low nitrogen supplementation $\left(2 \mathrm{~g} \cdot \mathrm{L}^{-1}\right)$, probably due to the high uncoupling between growth and production. Moreover, this coefficient can also be deduced from Figure 1, since it corresponds to the ratio of the production rate on the growth rate during the exponential growth phase.

Figure 2 clearly shows that high values for the coefficient $\mathrm{A}$ are not suitable, since they corresponded to low values for growth and production rates, and that they are not necessarily correlated with a high coupling between growth and production, as can be seen hereafter. This result was surprising, since it would be expected that the level of association increases with the coefficient for growth-associated production. This cannot be clearly pointed out by means of the plot of the product on biomass yield
(Fig. 2b), owing to the high lactose conversion, even at low rate.

These results showed that the coupling between g96rowth and production should preferably be analyzed by means of growth and production rates. However, since the objective is to maximize the part of acid produced during growth, i.e. during both associated and deceleration growth phase (cf. Introduction), comparison of both growth and production rate kinetics would be more suitable (Fig. 1). Indeed, the different growth phases can be easily characterized, and the time-variable appeared explicitly. This comparison has been conducted for the analysis of the effect of the main fermentation parameters on both the above growth phases.

\subsection{Preculture conditions}

The effect of preculture conditions on the subsequent culture was first considered (Fig. 3). The same culture medium, with a large nitrogen supplementation, has been used for all the experimentation (RM

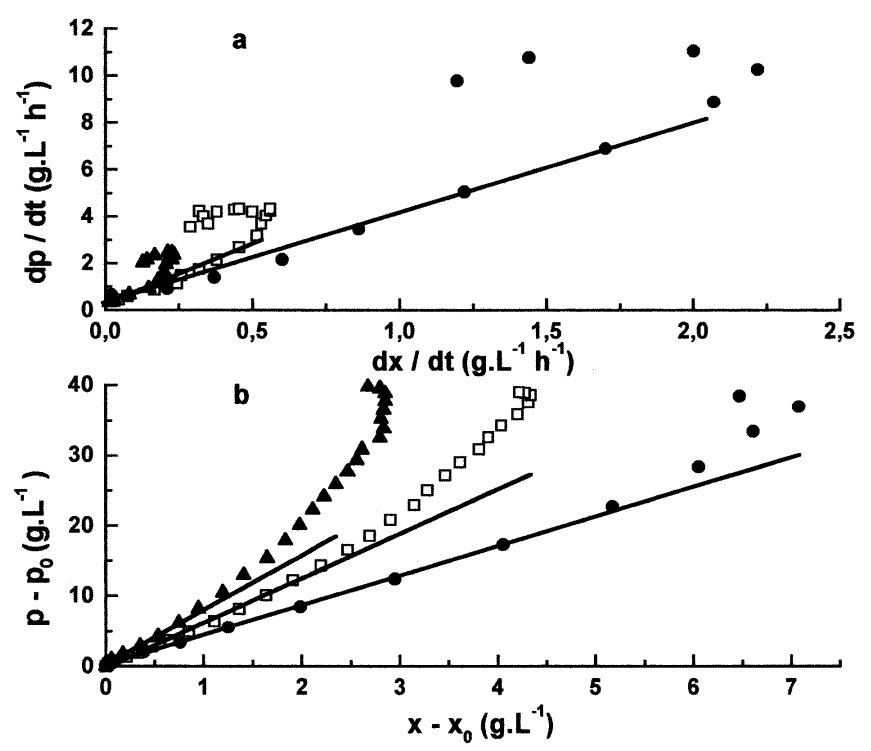

Figure 2. Production rate $\mathrm{dp} / \mathrm{dt}$ versus growth rate $\mathrm{dx} / \mathrm{dt}$ (a) and product on biomass yield $\mathrm{Y}_{\mathrm{P} / \mathrm{X}}(\mathbf{b})$ for L. helveticus growing on whey permeate supplemented with $20 \mathrm{~g} \cdot \mathrm{L}^{-1}$ yeast extract and $5 \mathrm{~g} \cdot \mathrm{L}^{-1}$ of both tryptic and pancreatic casein peptones (RM medium), at $\mathrm{pH}$ controlled at $(\mathbf{O}) 5.90$, ( $\square$ ) 4.63 and (A) 4.34, initially adjusted by addition of lactic acid. 
Figure 3. Part of the lactic acid produced during

the associated $\mathrm{p}_{\text {ass }}$ and

the deceleration growth

$\mathrm{p}_{\mathrm{dcl}}$ phases and coeffi-

cient A for the growth-

associated production (a,

$c, e)$, mean production

rates, during the whole

culture $r_{\text {pmean }}$ and both

the associated $r$ and

the deceleration $r_{\text {pdcl }}$

growth phases, as well as

growth phases, as well as

rate $r_{p \max }(b, d, f)$, for

cells growing on RM

medium and preculti-

vated:

- on whey supplemented

with a range of yeast

the RM supplemens or

-during $13.3 \mathrm{~h}, 8 \mathrm{~h}$ and $4.7 \mathrm{~h}(\mathrm{c}, \mathrm{d})$;

- for approximately $13 \mathrm{~h}$,

on $5 \mathrm{~g} \cdot \mathrm{L}^{-1}$ yeast extract

and inoculated at $11 \%$

seed level, on RM and

inoculated at $6.3 \%$ seed

level, on RM and inocu-
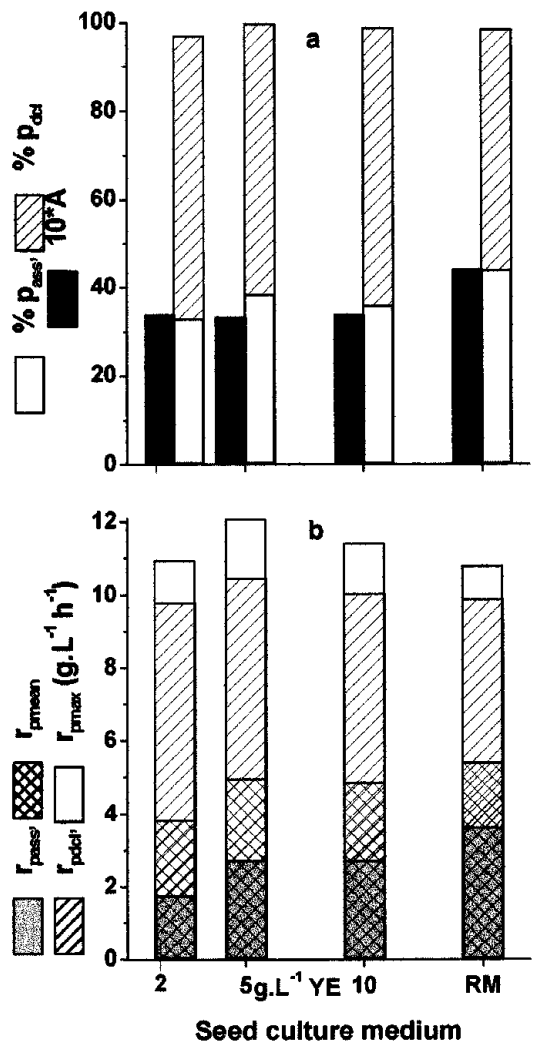

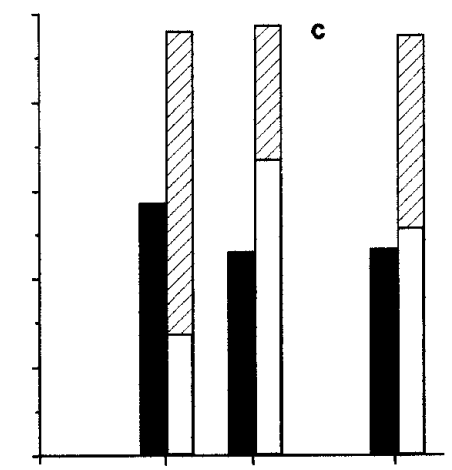

d

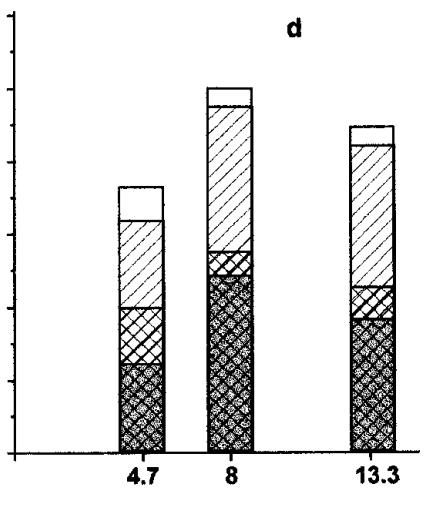

Seed culture length (h)

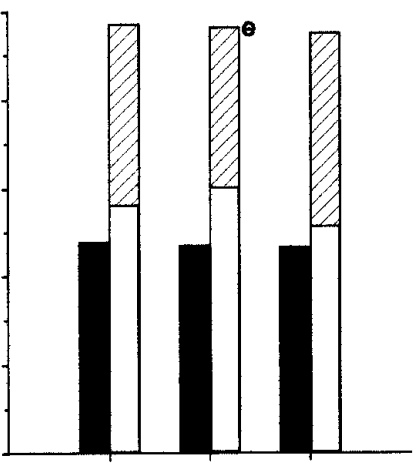

f

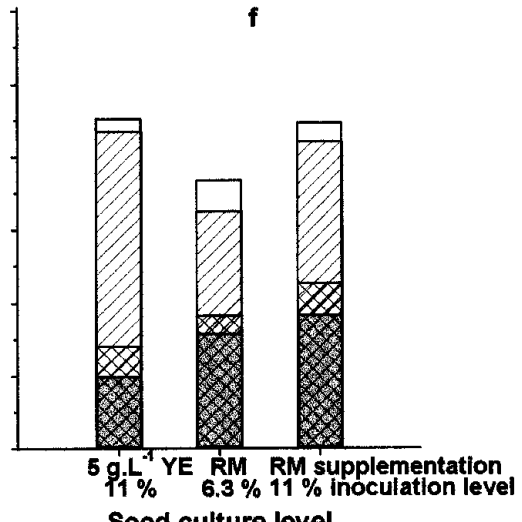

$(e, f)$. 
medium), to avoid any nutritional effect due to the non-metabolized nutrients arising from seed culture medium.

As observed in Figures 3a, $3 \mathrm{c}$ and $3 \mathrm{e}$, the same final amount of lactic acid was produced during both growth phases, associated and deceleration, irrespective of seed culture conditions; indeed for such a highly supplemented culture medium, the growth was carbon limited: the ends of growth and production coincided [3].

Preculture media have only a slight effect on the part of lactic acid produced by a coupled mechanism (varying between 33 and $43 \%$ for all the preculture media tested, Fig. 3a). Approximately the same length for the deceleration growth phase was recorded (2-2.5 h), while the length of the growthassociated phase decreased for larger nitrogen supplementation of preculture medium (Tab. II). These results show that preculture medium mainly influenced the length of the growth-associated phase. That was confirmed upon examination of volumetric productivities: there was no clear effect of preculture medium on maximum production rate $\left(\mathrm{r}_{\mathrm{pmax}}\right)$ and mean production rate during deceleration phase $\left(\mathrm{r}_{\mathrm{pdcl}}\right)$, while the mean production rate for both the whole culture $\left(r_{\text {pmean }}\right)$ and the growth-associated phase $\left(r_{\text {pass }}\right)$ increased for larger nitrogen supplementation of seed culture medium (Fig. 3b).

Up to $10 \mathrm{~g} \cdot \mathrm{L}^{-1}$ yeast extract supplementation in the preculture medium, close values for the coefficient A for growth-associated production were recorded during the subsequent culture (Fig. 3b). While this coefficient increased when cells were prepared on RM medium, a nutritional effect of the non-metabolized nutrients appeared, probably at high supplementation of preculture medium.

Table II. Effect of various preculture and culture conditions on the length of the associated $t_{\text {ass }}$ and the deceleration $t_{\mathrm{dcl}}$ growth phases.

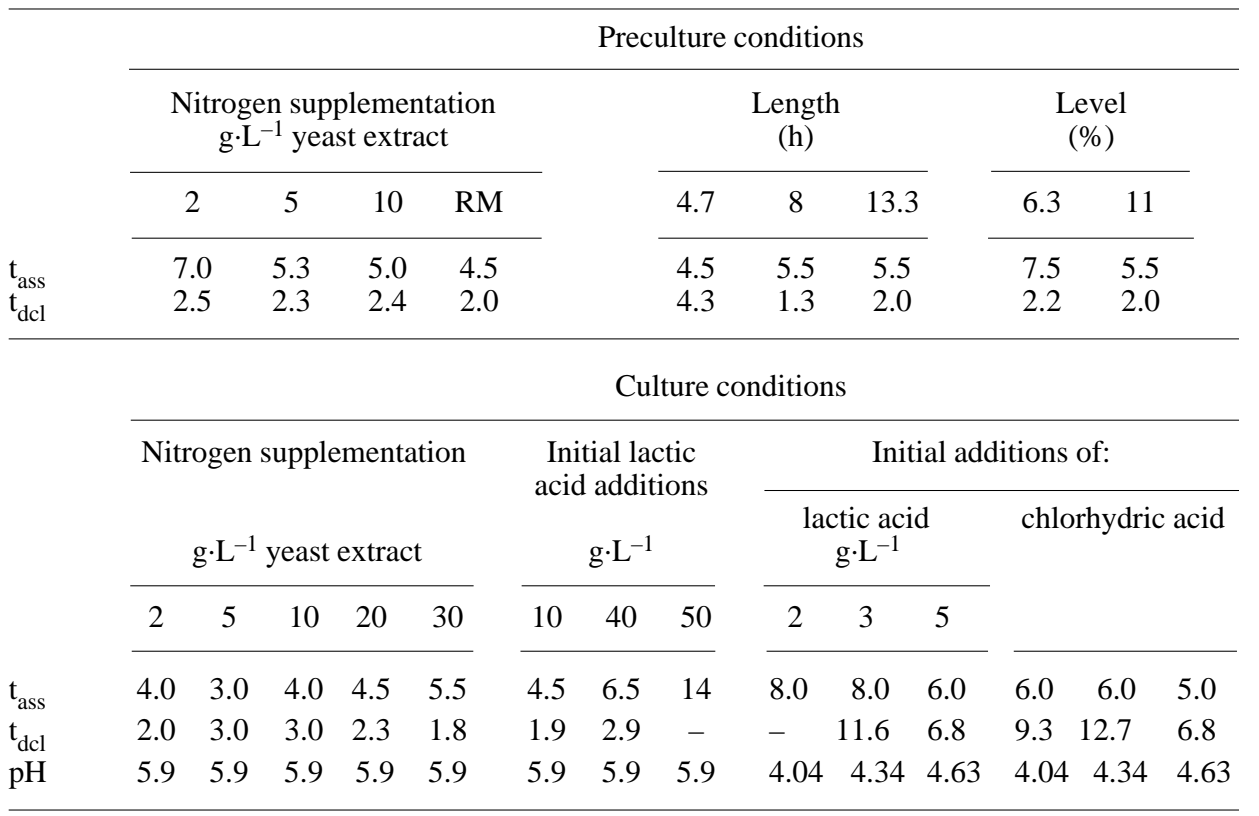


When the culture medium was inoculated with cells precultivated for $8 \mathrm{~h}$, the fermentation time was minimum (Tab. II) and all the production rates were maximum (Fig. 3d). In these conditions, the maximum for the part of lactic acid produced by an associated mechanism was observed (Fig. 3c); consequently, the minimum of lactic acid was produced during the deceleration growth phase. As observed above, in these culture conditions, all the lactic acid was produced during growth. The coefficient $\mathrm{A}$ also displayed a weak minimum when cells were prepared for $8 \mathrm{~h}$.

Up to $13 \mathrm{~h}$ of cell precultivation, there was no significant decrease in cellular activity, owing to the low decrease observed for the productivities (Figs. 3c and 3d). On the contrary, this was not the case when seed culture duration was too short.

To examine the effect of the inoculation level, a run has been carried out on RM medium, but inoculated at $6.3 \%(\mathrm{v} / \mathrm{v})$ instead of $11 \%$, with cells precultivated on RM medium too (Figs. 3e and 3f); additional pasteurized culture medium was fed into the fermentor to keep the total volume constant. As expected, when the inoculation level decreased, the productivities also decreased. This run at a $6.3 \%$ inoculation level was then compared to a culture inoculated at $11 \%$ with cells prepared on whey supplemented with $5 \mathrm{~g} \cdot \mathrm{L}^{-1}$ yeast extract; indeed, for both runs the same quantity of cells was inoculated. Lower mean production rate (Fig. 3f) and consequently longer fermentation time was observed, and such an increase in time concerned essentially the associated phase (Tab. II). Therefore, the difference between both inocula (prepared on whey supplemented with the RM supplementation and $5 \mathrm{~g} \cdot \mathrm{L}^{-1}$ yeast extract) was qualitative rather than quantitative.

\subsection{Nutritional limitations}

The part played by an associated mechanism in the total production increased continuously with the yeast extract (YE) supplementation, up to $57 \%$ for $30 \mathrm{~g} \cdot \mathrm{L}^{-1}$ yeast extract (Fig. 4a); this had to be brought together with previous results demonstrating that increasing YE supplementations resulted in a shift from a nitrogen limitation to a carbon one [6].

In the same way, the part of lactic acid produced during the deceleration growth phase increased up to $20 \mathrm{~g} \cdot \mathrm{L}^{-1}$ yeast extract supplementation (Fig. 4a), i.e. until the culture became carbon-limited; so an almost total production occurred during growth.

All the production rates also displayed a maximum for $20 \mathrm{~g} \cdot \mathrm{L}^{-1}$ YE supplementation (Fig. 4b), since above this concentration a toxic effect of yeast extract appears $[1,6]$. The product on biomass yield displayed a minimum value of 3.5 for $10 \mathrm{~g} \cdot \mathrm{L}^{-1}$ YE supplementation; as previously demonstrated by derivation of growth and production parameters with respect to the YE concentration $[6,8]$, this corresponded to the best performances at a minimum cost.

An effect of inorganic phosphorus has been shown for low YE supplementation of culture media [9]; this effect disappeared for high YE supplementation, owing to the high phosphorus content of the latter. Analysis of the different growth and production phases showed that this effect became nonnegligible during the stationary phase (data not shown).

\subsection{Inhibition}

The experiments displayed in Figure 5 were carried out on a medium largely supplemented (RM) to avoid any nitrogen and growth factor limitation.

At $\mathrm{pH}$ 5.9, the main inhibitory species, the undissociated lactic acid concentration $[11,12]$ could be neglected. So at this $\mathrm{pH}$, it seemed interesting to examine the effect of initial lactate additions on growth and production rates. As observed in Figure 5a, up to $40 \mathrm{~g} \cdot \mathrm{L}^{-1}$ of lactate initially added to the 


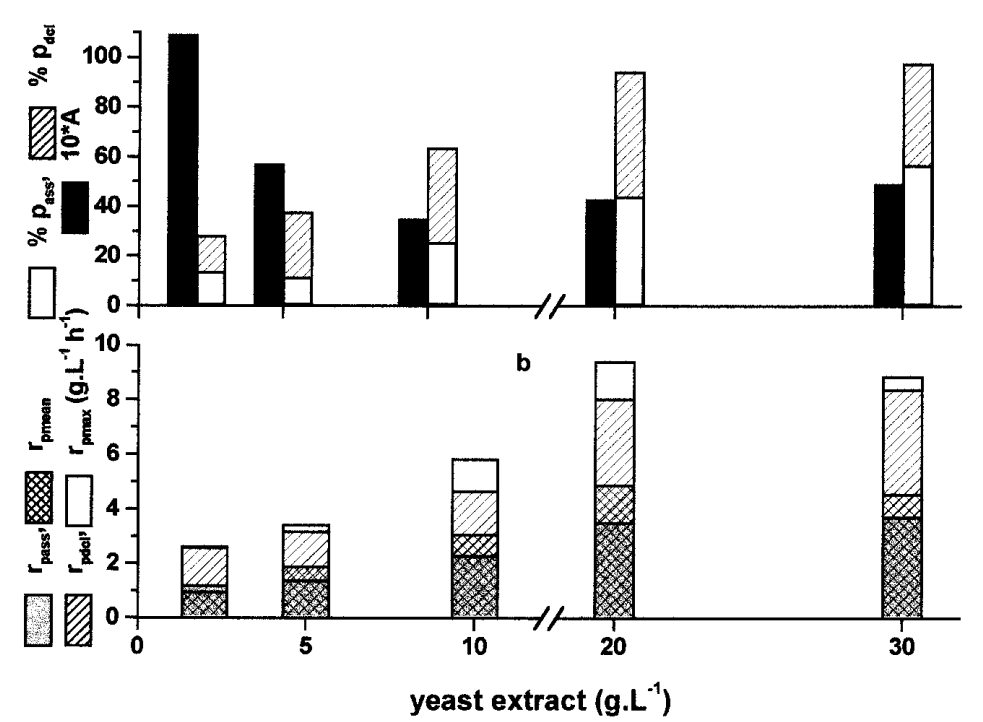

Figure 4. Part of the lactic acid produced during the associated $\mathrm{p}_{\mathrm{ass}}$ and the deceleration growth $\mathrm{p}_{\mathrm{dcl}}$ phases and coefficient $\mathrm{A}$ for the growth-associated production: (a) mean production rates, during the whole culture $r_{\text {pmean }}$ and both the associated $r_{\text {pass }}$ and the deceleration $r_{\text {pdcl }}$ growth phases, as well as maximum production rate $\mathrm{r}_{\mathrm{pmax}} ;$ (b) for $L$. helveticus growing on whey permeate supplemented with a range of yeast extract concentrations.

culture medium, almost all the production occurred during growth; the part of lactic acid produced by an associated mechanism and during the deceleration phase varied only very slightly, but in the opposite sense. For $50 \mathrm{~g} \cdot \mathrm{L}^{-1}$ of lactate added, the critical concentration $\left(83 \mathrm{~g} \cdot \mathrm{L}^{-1}\right)$ was achieved before a total lactose exhaustion.

On the other hand, the fermentation time increased from $40 \mathrm{~g} \cdot \mathrm{L}^{-1}$ lactate initially added, both associated and deceleration growth phases length increased (Tab. II). Therefore, the inhibitory effect of the lactate anion appeared only for $40 \mathrm{~g} \cdot \mathrm{L}^{-1}$ of lactate initially added. This can also be pointed out upon examination of Figure 5b, since maximum and mean production rates decreased for this lactate addition, while the coefficient A increased.

As observed, when the $\mathrm{pH}$ control decreased, the concentration of the inhibitory specy $[11,12]$, the undissociated lactic acid, increased, and the amount of lactic acid produced by an associated mechanism decreased. Moreover, at $\mathrm{pH} 4.34$ for an initial addition of lactic acid and at $\mathrm{pH} 4.04$ for an initial addition of hydrochloric acid, a shift from a nutritional limitation (carbon) to an inhibition by the accumulated free lactic acid was observed for the cessation of growth, since the inhibitory concentration level of $8.5 \mathrm{~g} \cdot \mathrm{L}^{-1}$ had been achieved [7].

As expected, growth duration, including both associated and deceleration growth phases, increased when $\mathrm{pH}$ control decreased, up to $\mathrm{pH} 4.34$ (Tab. II). At pH 4.04, the inhibitory effect of $\mathrm{pH}$ induced poor growth at a low rate. All the production rates decreased at acidic $\mathrm{pH}$, while the coefficient $\mathrm{A}$ increased (Figs. 5d and 5f).

At a given $\mathrm{pH}$ control, an initial addition of lactic acid has been compared to an initial addition of hydrochloric acid, in order to differentiate the inhibitory effect of the 

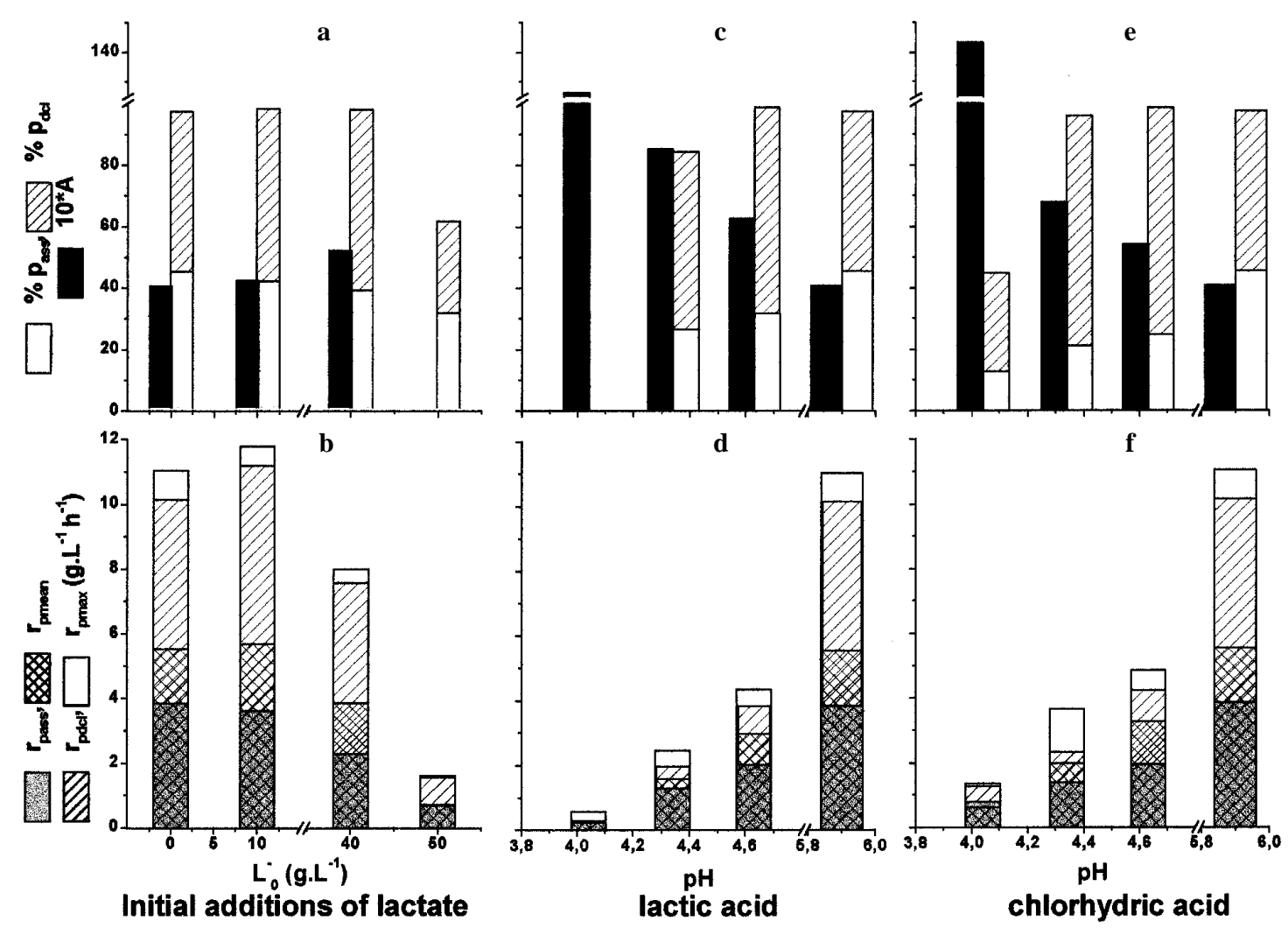

Figure 5. Part of the lactic acid produced during the associated $\mathrm{p}_{\mathrm{ass}}$ and the deceleration $\mathrm{p}_{\mathrm{dcl}}$ growth phases and coefficient A for the growth-associated production $(\mathbf{a}, \mathbf{c}, \mathbf{e})$, mean production rates, during the whole culture $r$ and both the associated $r$ and the deceleration $r$ growth phases, as well as maxis tic and pancreatic casein peptones (RM medium): at pH 5.90, with initial additions of lactate $\left(0-10-40-50 \mathrm{~g} \cdot \mathrm{L}^{-1}\right)(\mathbf{a}, \mathbf{b})$, and at different $\mathrm{pH}$ control $(5.90-4.63-4.34-4.04)$, initially adjusted by addition of lactic acid $(\mathbf{c}, \mathbf{d})$ or hydrochloric acid $(\mathbf{e}, \mathbf{f})$ 
undissociated lactic acid from the $\mathrm{pH}$ effect. As observed from the comparison of Figures $5 \mathrm{c}$ and $5 \mathrm{e}$ on one hand and Figures $5 \mathrm{~d}$ and $5 \mathrm{f}$ on the other hand, it appeared that growth and production depended mainly on $\mathrm{pH}$, and to a lesser extent on the undissociated lactic acid concentration. Indeed, an initial addition of lactic acid to set the required $\mathrm{pH}$ control resulted not only in a slightly higher growth length and product on biomass yield $\mathrm{Y}_{\mathrm{P} / \mathrm{X}}$, but also in slightly lower maximum and mean production rates, if compared to an initial addition of hydrochloric acid to adjust the $\mathrm{pH}$.

\section{CONCLUSION}

The bioconversion of lactose into lactic acid was optimized when a maximum amount of lactic acid was produced during growth, i.e. during the associated and the deceleration growth phases. Maximum production rates were always observed $0.5-1 \mathrm{~h}$ after the maximum of growth rates, i.e. in the beginning of the deceleration phase. From this, production rates during the growthassociated phase were close to mean production rates on one hand, and production rates recorded during the deceleration phase were close to the maximum rates on the other hand. On the contrary, only low productivities were recorded during the stationary state, corresponding to the maintenance of cells.

The main parameter during seed culture appeared to be its duration since it affected production rates; the optimal duration was about $5 \mathrm{~h}$. As expected, the production rates increased with the inoculation level; therefore the ratio productivity gain on the increase in the inoculation level have to be optimized.

During culture, and as expected, the production rates increased with the nitrogen supplementation of culture media; therefore the gain in the productivity has to be considered with respect to the increase in the nitrogen supplementation.
On whey, no inhibitory effect of the lactate can be observed, since below $40 \mathrm{~g} \cdot \mathrm{L}^{-1}$ there was no effect of this component on production parameters. The optimal $\mathrm{pH}$ was 5.9; lower $\mathrm{pH}$ control affected all the production parameters.

\section{ACKNOWLEDGEMENTS}

The author thanks Prof. Y. Prigent for helpful discussions and Ms A. Copeland for correcting this manuscript.

\section{REFERENCES}

[1] Aeschlimann A., von Stockar U., The effect of yeast extract supplementation on the production of lactic acid from whey permeate by $L a c$ tobacillus helveticus, Appl. Microbiol. Biotechnol. 32 (1990) 398-402.

[2] Amrane A., Prigent Y., A novel concept of bioreactor: specialized function two-stage continuous reactor, and its application to lactose conversion into lactic acid, J. Biotechnol. 45 (1996) 195-203.

[3] Amrane A., Prigent Y., Growth and lactic acid production coupling for Lactobacillus helveticus cultivated on supplemented whey: influence of peptidic nitrogen deficiency, J. Biotechnol. 55 (1997) 1-8

[4] Amrane A., Prigent Y., Identification and experimental validation of a criterion allowing prediction of cellular activity for preculture of lactic acid bacteria, J. Ferment. Bioeng. 85 (1998) 328-333.

[5] Amrane A., Prigent Y., Lactic acid production rates during the different growth phases of $\mathrm{Lac}$ tobacillus helveticus cultivated on whey supplemented with yeast extract, Biotechnol. Lett. 20 (1998) 379-380.

[6] Amrane A., Prigent Y., Influence of yeast extract concentration on batch cultures of Lactobacillus helveticus: growth and production coupling, World J. Microbiol. Biotechnol. 14 (1998) 529-534.

[7] Amrane A., Prigent Y., Differentiation of $\mathrm{pH}$ and free lactic acid effects on the various growth and production phases of Lactobacillus helveticus, J. Chem. Technol. Biotechnol. 74 (1999) 33-40.

[8] Amrane A., Prigent Y., Analysis of growth and production coupling for batch cultures of $L a c$ tobacillus helveticus with the help of an unstructured model, Process Biochem. 34 (1999) 1-10. 
[9] Amrane A., Effect of inorganic phosphate on lactate production by Lactobacillus helveticus grown on supplemented whey permeate, J. Chem. Technol. Biotechnol. 75 (2000) 1-6.

[10] Fauquant J., Viéco A., Brulé G., Maubois J.-L., Sweet whey clarification by heat-calcium aggregation of residual fat material, Lait 65 (1985) $1-20$.

[11] Gätje G., Gottschalk G., Limitation of growth and lactic acid production in batch and continuous cultures of Lactobacillus helveticus, Appl. Microbiol. Biotechnol. 34 (1991) 446-449.

[12] Kashket E.R., Bioenergetics of lactic acid bacteria: cytoplasmic $\mathrm{pH}$ and osmotolerance, FEMS Microbiol. Rev. 46 (1987) 233-244.

[13] Luedeking R., Piret E.L., A kinetic study of the lactic acid fermentation. Batch process at controlled pH, J. Biochem. Microbiol. Technol. Eng. 1 (1959) 393-412.
[14] Norton S., Lacroix C., Vuillemard J.-C., Kinetic study of continuous whey permeate fermentation by immobilized Lactobacillus helveticus for lactic acid production, Enzyme Microb. Technol. 16 (1994) 457-466.

[15] Roy D., Le Duy A., Goulet J., Kinetics of growth and lactic acid production from whey permeate by Lactobacillus helveticus, Can. J. Chem. Eng. 65 (1987) 597-603.

[16] Turner K.W., Thomas T.D., Uncoupling of growth and acid production in lactic Streptococci, N. Z. J. Dairy Sci. Technol. 10 (1975) 162-167.

[17] Venkatesh K.V., Okos M.R., Wankat P.C., Kinetic model of growth and lactic acid production from lactose by Lactobacillus bulgaricus, Process Biochem. 28 (1993) 231-241. 